\title{
Effect of laser on the remnant liver after the first 24 hours following $70 \%$ hepatectomy in rats ${ }^{1}$
}

\author{
Efeito do laser no fígado remanescente nas primeiras 24 horas \\ após hepatectomia a $70 \%$ em ratos
}

\begin{abstract}
Ailton Jose Barbosa ${ }^{\mathrm{I}}$, Ana Carolina Delazia Albuquerque Santana ${ }^{\mathrm{II}}$, Tiago Castro e Silva ${ }^{\mathrm{III}}$, Cristina Kurachi' ${ }^{\mathrm{IV}}$, Natalia Inada ${ }^{\mathrm{IV}}$, Vanderlei Salvador Bagnatov, Orlando de Castro e Silva Jr ${ }^{\mathrm{VI}}$

${ }^{\mathrm{I}} \mathrm{PhD}$, Assistant Professor, Division of Digestive Surgery, Department of Surgery and Anatomy, FMRP-USP, Ribeirao Preto-SP, Brazil. Acquisition and interpretation of data.

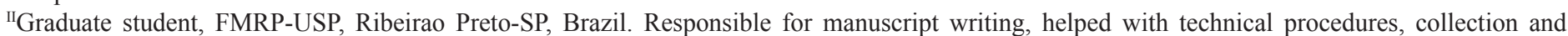
processing of study information.

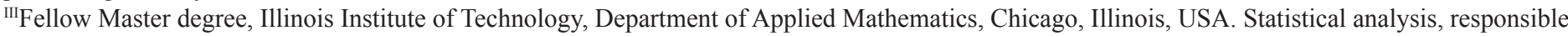
for the English language.

${ }^{\text {IV }} \mathrm{PhD}$, Assistant Professor, Department of Biophotonics, Institute of Physics of Sao Carlos, USP, Sao Carlos-SP, Brazil. Critical revision.

${ }^{\vee}$ Full Professor, Institute of Physics of Sao Carlos, USP, Sao Carlos-SP, Brazil. Supervised all phases of the study.

${ }^{\mathrm{VI}}$ Chairman and Head, Department of Surgery and Anatomy, FMRP-USP, Ribeirao Preto-SP, Brazil. Critical revision, supervised all phases of the study, responsible for manuscript writing.
\end{abstract}

\begin{abstract}
PURPOSE: To evaluate the mitochondrial function of the remnant liver (RL) in the early phase of liver regeneration in rats after $70 \%$ partial hepatectomy $(\mathrm{PH})$.

METHODS: Sixty male Wistar rats (200-250g) submitted to 70\% PH were divided into five groups according to the time of euthanasia and application or not of laser light: $\mathrm{C}=\mathrm{Control}$, time zero; 2 minutes, 4, 6 and 24 hours after PH. The dose of laser radiation was $22.5 \mathrm{~J} / \mathrm{cm}^{2}$, wavelength of $660 \mathrm{~nm}$ (visible/red), in the remnant liver. We studied the respiration activated by ADP (state 3), basal mitochondrial respiration (state 4), respiratory control ratio (RCR) and mitochondrial membrane potential (MMP).

RESULTS: The mitochondrial function of RL changed at 4 and 6 hours after PH, with a significant increase in state 3 and a concomitant increase in state 4 and with maintenance of RCR. MMP differed significantly between the groups biostimulated with laser radiation and the control group 4 hours after HP, with a substantial reduction in the non-laser groups.

CONCLUSION: The laser light at the dose used in this study did not induce additional damage to the RL and seems to have delayed the hepatocellular metabolic overload of the remnant liver.

Keywords: Laser. Liver. Hepatectomy. Mitochondria. Liver Regeneration. Rats.

\section{RESUMO}

OBJETIVO: Avaliar a função mitocondrial do fígado remanescente (FR) na fase precoce da regeneração hepática em ratos após hepatectomia parcial (HP) a $70 \%$.

MÉTODOS: Sessenta ratos machos Wistar $(200$ - 250g) submetidos à HP a 70\%, foram distribuídos em cinco grupos de acordo com o tempo de eutanásia e com aplicação ou não de luz laser: $\mathrm{C}=$ Controle,tempo zero; 2 minutos, 4 , 6 e 24 horas após HP. O laser foi utilizado na dose $22.5 \mathrm{~J} / \mathrm{cm}^{2}, 660 \mathrm{~nm}$, no FR.Estudou-se o estado 3 (respiração ativada por ADP), estado 4 (respiração mitocondrial basal), razão de controle respiratório, estado 3/estado 4 (RCR) e o potencial de membrana mitocondrial(PMM).

RESULTADOS: A função mitocondrial do FR alterou-se no período de 4 e 6 horas após a HP com aumento significativo do estado 3 e aumento concomitante do estado 4, com manutenção da RCR. O PMM apresentou diferença significativa entre os grupos bioestimulados com laser e o controle a partir de 4 horas pós HP, com queda importante do grupo sem laser e tendência a equiparação dos valores após 24 horas.
\end{abstract}

CONCLUSÃO: A luz laser, na dose utilizada no presente estudo, não induziu lesão adicional ao FR e parece ter retardado a sobrecarga hepatocelular do fígado remanescente.

Descritores: Lasers. Fígado. Hepatectomia. Mitocôndria. Regeneração Hepática. Ratos. 


\section{Introduction}

After $70 \%$ partial hepatectomy $(\mathrm{PH})^{1}$, proliferation of hepatocytes occurs almost synchronously throughout the tissue, whereas differentiated liver function is maintained to meet the demands of the organism. Since the animal's liver has about 8 $\mathrm{x} 10^{7}$ cells, it can be concluded that a single hepatocyte has the clonogenic potential to produce $7 \times 10^{12}$ livers, similar to the potential of hematopoietic progenitor cells. This finding is quite unexpected, given the high ploidy and the complexity of the functions performed by hepatocytes ${ }^{2}$.

Regeneration can be experimentally induced by any chemical, surgical or acute challenge which removes or destroys a large percentage of hepatic parenchyma. The tissue loss in the remnant liver $(\mathrm{RL})$ rapidly triggers the regenerative process until the original weight is regained ${ }^{3}$. Concomitant with the regeneration, the RL reduced in size needs to keep its metabolic functions intact and adapt to the new hemodynamic conditions imposed by the new container/content relationship of the RL.

The liver regenerative process is recognized as a spectacular example of orderly and organized tissue growth controlled by multiple signals from cytokines and growth factors. There is complete restoration of liver mass, even after extensive acute cell damage, such as in toxic and viral fulminant hepatitis, after extensive surgical ablations, segmental resections due to large tumor masses and acute traumatic injuries, or after transplantation of liver segments ${ }^{3}$.

Although the term regeneration is commonly used, it is biologically incorrect, since the response induced by resection of liver tissue is not truly regenerative. The resected lobes do not grow again. The restoration of liver mass occurs by compensatory cellular hyperplasia in the remaining lobes, with a consequent increase in its dimensions. This suggests that liver growth is controlled by functional factors rather than anatomical factors. Whatever the nature of these factors, they seem to be quite accurate since the growth ceases when the liver reaches its original weight.

The process of liver regeneration is dependent on energy whose primary source is mitochondrial energy. After resection of the liver parenchyma, there is an increase of mitochondrial function in order to provide the RL with the energy required for the restoration of liver mass by hyperplasia and cellular hypertrophy. Therefore, the success of liver resection depends on the metabolic and regenerative capacity of the RL and is directly related to the continuous supply of energy produced by mitochondria ${ }^{4}$.

Additionally, the ability of laser light to interfere in the process of liver regeneration was demonstrated. In this experiment, there was an increase in hepatic mitotic and mitochondrial activities promoted by photobiostimulation which was assessed on the basis of oxidative phosphorylation and proliferating cell nuclear antigen ${ }^{5}$.

Thus, the purpose of the present study was to evaluate changes in mitochondrial function in the early phase of RL regeneration after $70 \% \mathrm{PH}$, and the effect of laser light on the hepatic mitochondria in this situation.

\section{Methods}

A total of 60 male Wistar rats weighing 200-250g were used. The animals were supplied by the Central Animal Facility of the Ribeirao Preto Campus, University of Sao Paulo, fed standard crow for laboratory rats (Purina Nutrimentos Ltda.) and receiving water ad libidum. The animals were kept in the Animal Facility of the Laboratory of Surgical Technique and Experimental Surgery, Department of Surgery and Anatomy, Faculty of Medicine of Ribeirao Preto, University of Sao Paulo, at room temperature, under a 12 hour light-dark cycle, in transparent polypropylene cages with a galvanized wire cover, measuring $41 \times 34$ x $16 \mathrm{~cm}$, with a maximum population of five animals.

Animals were anesthetized with ethyl ether inhalation, kept in the supine position, and after $\mathrm{PH}$ of approximately $70 \%$ of the liver ${ }^{1}$, they were divided into 10 groups of six animals each $(\mathrm{n}=6)$, according to time of euthanasia $(\mathrm{C}=$ Control, 0 minutes, 2 minutes, 4, 6 and 24 hours), and according to whether or not the laser light was applied.

The RL was irradiated at 5 different points with red light helium neon laser with a wavelength of $660 \mathrm{~nm}$ and power of 50 $\mathrm{mW}$ for a period of 30 seconds per point at a dose of $22.5 \mathrm{~J} / \mathrm{cm}^{2}$ in each point, immediately after $70 \% \mathrm{PH}$. Later, after a pre-set period of time ( $\mathrm{C}=0$ ', 2', 4 and 12 hours), the RL was collected and the animals were euthanized by exsanguination.

Samples of the resected liver were collected at the time of sacrifice for biochemical analysis of mitochondrial function respiration activated by ADP and basal mitochondrial respiration, respiratory control ratio (RCR) and membrane potential ${ }^{6}$.

\section{Mitochondrial isolation and oxygen consumption}

Isolation of liver mitochondria was performed by differential centrifugation ${ }^{7}$. Mitochondrial oxygen consumption was analyzed polarographically with a homemade oxygraph constructed at IFSC-USP equipped with a Clarck oxygen electrode, and the respiratory parameters were determined according to an established procedure. Succinate $(5 \mathrm{mM})$ was 
used as oxidizable substrate in $1.4 \mathrm{ml}$ of medium containing $125 \mathrm{mM}$ sucrose, $65 \mathrm{mM} \mathrm{KCl}, 1 \mathrm{mM} \mathrm{MgCl}, 2 \mathrm{mM} \mathrm{KH}_{2} \mathrm{PO}_{4}$, $0.1 \mathrm{mM}$ EGTA, and $10 \mathrm{mM}$ Hepes-KOH, $\mathrm{pH}$ 7.4; and $2 \mathrm{mg}$ of mitochondrial protein were used. State 3 respiration was induced with $400 \mathrm{nmol} \mathrm{MgADP}$, and state 4 respiration (basal mitochondrial respiration) was determined afterphosphorylation of additional $\mathrm{ADP}^{8}$. The ratio between state 3 and state 4 rates (RCR), which represents coupling between electron transport and oxidative phosphorylation, was determined.

\section{Electrical transmembrane potential difference ( $\Delta \psi)$}

Electrical transmembrane potential difference $(\Delta \psi)$ was monitored spectrofluorimetrically by using $5 \mu \mathrm{M}$ safranine-O as an indicator and an SLM-Aminco, Bowman, series 2, luminescence spectrophotometer at a 495/586 nm excitation/emission wavelength pair ${ }^{9}$. Assays were performed in an incubation medium containing $200 \mathrm{mM}$ sucrose, $1 \mathrm{mM}$ $\mathrm{MgCl}_{2}, 2.5 \mathrm{mM} \mathrm{NaH}_{2} \mathrm{PO}_{4}$, and $10 \mathrm{mM}$ Hepes-KOH at $\mathrm{pH}$ 7.4. Mitochondria were energized with $5 \mathrm{mM}$ sodium succinate. The membrane potential variation was expressed as $\mathrm{mV}$ as usual.

Results of various groups were compared and analyzed using the non-parametric Wilcoxon-Mann-Whitney test, considering $\mathrm{p}<0.05$ as the critical value for statistical significance.

\section{Results}

In this study, we determined that the mitochondrial function of the RL changed, especially at 4 and 6 hours after $\mathrm{PH}$, with a significant increase of respiration activated by ADP (state 3) and a concomitant increase in basal mitochondrial respiration (state 4), (Figure 1) and with maintenance of the RCR (Figure 2, panel A). Under the same conditions, there was a significant reduction in the electrical potential of the mitochondrial membrane (Figure 2, panel B), without significant evidence of mitochondrial swelling (data not shown).

We observed that 24 hours after PH the respiratory parameters (state 3, state 4 and RCR) returned to control levels (Figure 1, panels A and B and Figure 2, panel A). Regarding state 3 , laser radiation led to a significant decrease in respiratory rate activated by ADP 4 hours, but not 6 hours after PH. Laser radiation did not alter the state 4 of mitochondrial respiration compared to control and, although reducing the levels of RCR 4 hours after $\mathrm{PH}$, it did not cause mitochondrial uncoupling (Figures 1 and 2).
In the first two minutes, significant effects on mitochondrial bioenergetic function were not observed in the presence or absence of laser biostimulation. The most significant effects were observed 2 and 6 hours after $\mathrm{PH}$ in the presence and absence of laser radiation, returning to control levels 24 hours after $\mathrm{PH}$.
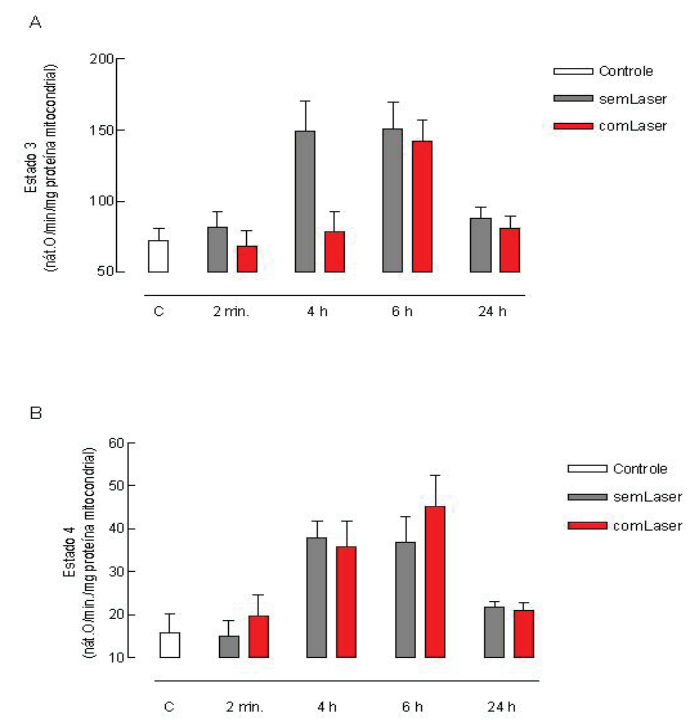

FIGURE 1 - Analysis of mitochondrial bioenergetic before PH (C: control) and after PH (2 min, 4h, 6h, $24 \mathrm{~h}$ ), in the presence and absence of laser biostimulation. Panels A and B: mitochondrial respiration rates (state 3 and 4 , respectively).

A
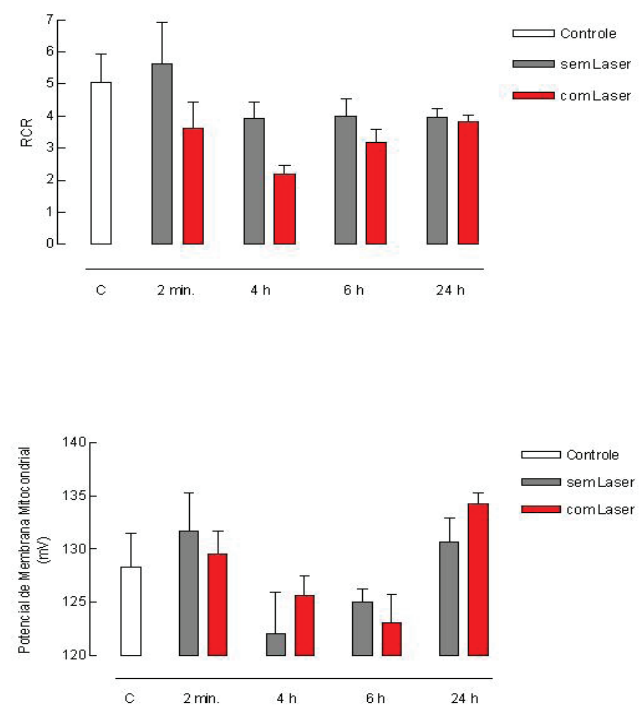

FIGURE 2 - Analysis of mitochondrial bioenergetic before $\mathrm{PH}$ (C: control) and after PH (2 min, 4h, 6h, $24 \mathrm{~h})$, in the presence and absence of laser biostimulation. Panel A: values of respiratory control ratio (RCR); Panel B: values of mitochondrial membrance potential. 


\section{Discussion}

After partial $\mathrm{PH}$, the $\mathrm{RL}$ will be responsible for maintaining the life of the host. During the first hours and days after resection, it will undergo intense changes necessary to maintain its viability and therefore the maintenance of life of the host. Moreover, the greater the extent of parenchyma resected, the greater the adaptation of the RL to the new metabolic and hemodynamic conditions that occur due to the reduction of the hepatic parenchyma.

After PH, the RL goes into a state of metabolic overload ${ }^{10}$. Some authors indicate situations in which, after $\mathrm{PH}$, the liver regeneration was significantly delayed by a resistance increased by a growth factor related to insulin by mechanisms mediated by oxidative stress ${ }^{10}$.

Due to reduction of the parenchyma, the RL must quickly adapt to the new hemodynamic conditions, keep its metabolism intact and still start the regeneration process. As mentioned earlier, the term regeneration is biologically incorrect. In fact what happens is intense hyperplasia and hypertrophy of RL parenchyma until it reaches its original weight, approximately one week after surgery in rats, when the regenerative process begins to decline until it stops around the 21 st day.

Much of the increase of liver mass occurs three hours after PH and most of the liver mass is obtained within up to seven days. Several potential hepatocyte growth factors, such as HGF, TGFx and the anti-proliferative factor TGFb are identified early after PH. Likewise, it is known that more than 100 immediateearly genes which are activated by normally latent transcription factors in the transition between G0 and G1 show a significant action before the beginning of the new protein synthesis. It is also known that the peak of DNA synthesis in hepatocytes occurs at about 24 hours while the peak of DNA in non-parenchymal cells occurs at about 36 to 48 hours after PH. It follows that the demand for energy needed for maintenance of hepatocellular function is increased in an RL already overburdened by its new anatomical and functional condition ${ }^{10}$

In this study, we found that the mitochondrial changes in the RL that occurred in the first 24 hours after PH were detected mainly in the first six hours after PH. At four and six hours after $\mathrm{PH}$, we observed a significant increase in cellular respiration activated by ADP, which is compatible with the highest energy requirement by the cell at this early stage of liver regeneration and hemodynamic adaptation of the RL. During this period there was a concomitant increase in basal mitochondrial respiration which suggested a trend to uncoupling oxidative phosphorylation, probably due to the metabolic overload that occurs in the RL. In this metabolic overload, due to the reduced or altered membrane potential, the cell membranes cannot meet the increased demand of the process of phosphorylation of ADP for ATD production. The use of laser light, which stabilized mitochondrial membranes, improved mitochondrial function with an increased rate of respiratory control, particularly six hours after $\mathrm{PH}$.

In the state 4 respiration rate, laser radiation did not induce a change compared to the liver mitochondria that did not receive biostimulation (Figure 1, panel B). At four and six hours post-PH, the significant increase of this condition (state 4) was due mainly to the involvement of the opening of the mitochondrial permeability transition pore (MPTP), which facilitates the leakage of protons through the membrane, observed both by the increase in breathing at rest (state 4), and by the significant decrease in mitochondrial membrane potential (Figure 2, panel B). These two conditions were not altered by the action of a laser biostimulator because its effect is not able to regenerate and reverse the opening of pores in mitochondrial membranes. In future work, prior treatment of mitochondria isolated with the MPTP opening inhibitor, cyclosporin A, could be performed to corroborate the cited evidence obtained with specific antioxidants to evaluate the participation of the production of reactive oxygen species at the MPTP opening.

In previous work from our group, there was an increase of liver regeneration by laser light across the entire visible light spectrum analyzed ${ }^{5}$. Thus, the results of the present study suggest that there was a change of metabolic overload induced by laser light. This reduction in metabolic overload may determine the increase in liver regeneration observed in other studies.

These data reinforce the finding of other studies and suggest that metabolic overload of RL induced by hepatectomy per se, indicated in a sensitive way by mitochondrial alterations found in the first hours after hepatectomy ${ }^{11,12}$, is probably a consequence of an imbalance between energy supply and demand of the remnant liver ${ }^{13,14}$.

We can conclude that the remaining tissue depends on mitochondrial oxidative phosphorylation to meet the energy demand and defects indicative of a mitochondrial permeability transition have been reported in isolated mitochondria of RL after $\mathrm{PH}$. With the hepatocellular adaptation, the mitochondrial changes found normalize over the hours after resection, when RL acquires a new metabolic status, evidenced by normalization of most mitochondrial parameters in a compensatory growth mechanism of $\mathrm{RL}^{15}$. 
Measurements of cytosolic calcium ion concentration and reactive oxygen species are important and suitable for future work, since it is known that high levels of potassium promote oxidative stress of membrane thiol groups of NADPH, leading to the opening of the MPTP, which would explain both the increased rate of $\mathrm{O}_{2}$ consumption in state 4 and the significant decrease in mitochondrial membrane potential ${ }^{16}$.

Further analysis as a measure of ATP levels post-PH can support what has been observed here, i.e., a significant drop in the quantities of post-PH nucleotide, which is directly related to the early signs of mitochondrial oxidative stress in the process of liver regeneration ${ }^{17}$.

\section{Conclusion}

Laser light (helium neon) at the dose used in this study, did not induce further damage to the RL and seemed to delay the hepatocellular metabolic overload of the liver remnant, measured by the set of mitochondrial alterations.

\section{References}

1. Higgins GM, Anderson RM. Experimental pathology of the liver: 1. Restoration of the liver of the white rat following partial surgical removal. Arch Pathol. 1931;12:186-202.

2. Verturf K, Al-Dhalimy M, Ou CN, Finegold M, Grompe M. Serial transplantation reveals the stem-cell-like regenerative potential of adult mouse hepatocytes. Am J Pathol.1997;151:1273-80.

3. Mitchell P. Coupling of pho holylaoon to electron and hydrogen transfer by a chemiosmotic type of mechanism. Nature.1961;191:144-8.

4. Parks RW, Chrysos E, Diamond T. Management of liver trauma. $\mathrm{Br}$ J Surg. 1999;86:1121-35.

5. Silva Junior OC, Zucoloto S, Marcassa LG, Kurachi C, Melo CAS, Ramalho FS, Ramalho LNZ, Bagnato VS. Spectral response for laser enhancement in hepatic regeneration for hepatectomized rats. Laser Surg Med. 2003;32:50-3.

6. Chance B, Willians GR. The respiration enzymes in oxidative phosphorylation. J Biol Chem.1956;217:409-27.

7. Pedersen PL, Greenawalt JW, Sper JW, Bustamente E. Preparation and characterization of mitochondria and submitochondrial particles of rat liver and liver-derived tissues. Methods Cell Biol.1978;20:411-81.

8. Souza MEJ, Polizello ACM, Uyemura SA, Castro e Silva Jr, Curti C. Effect of fluoxetine on rat liver mitochondria. Biochem Pharmacol.1994;48:535-41.
9. Jordani MC, Santos AC, Prado IM, Uyemura SA, Curti C. Flufenamic acid as an inducer of mitochondrial permeability transition. Mol Cell Biochem. 2000;210:153-58.

10. Chamuleau RA, Bosman DK. Liver regeneration. Hepatogastroenterology. 1989;35:309-12.

11. Riehle KJ, Dan YY, Campbel JS, Fausto N. New concepts in liver regeneration. J Gastroenterol Hepatol. 2011;26:203-12.

12. Guerrieri F, Vendemiale G, Grattagliano I, Cocco T, Pellechia G, Altomare E. Mitochondrial oxidative alterations following partial hepatectomy. Free Radic Biol Med.1999;26:34-41.

13. Rabes HM, Wirshing R, Tuczek HV, Isseler G. Analysis of cell cycle compartments of hepatocytes after partial hepatectomy. Cell Tissue Kinet. 1976;6:517-32.

14. Sherman HF, Savage BA, Jones LM, Barrette RR, Latenser BA, Varcelotti Jr. Nonoperative management of blunt hepatic injuries: safe at any grade? J Trauma. 1994;37:616-21.

15. Greco M, Moro L, Pellecchia G, Di Pede S, Guerrieri F. Release of matrix proteins from mitochondria to cytosol during the prereplicative phase of liver regeneration. FEBS Lett.1998;427:179-82.

Babizhayev MA. Mitochondria induce oxidative stress, generation of reactive oxygen species and redox state unbalance of the eye lens leading to human cataract formation: disruption of redox lens organization by phospholipid hydroperoxides as a common basis for cataract disease. Cell Biochem Funct. 2011;29:183-206.

16. Crumm S, Cofan M, Juskeviciute E, Hoek JB. Adenine nucleotide changes in the remnant liver: an early signal for regeneration after partial hepatectomy. Hepatology. 2008;48:1-11.

\section{Correspondence:}

Orlando Castro e Silva Junior

Rua Campos Salles, 890/92

15015-110 Ribeirão Preto-SP Brasil

Tel.: (55 19)3602-2242

orlando@,fmrp.usp.br

\section{Conflict of interest: none}

Financial source: FAPESP

${ }^{1}$ Research performed at Department of Surgery and Anatomy, Ribeirao Preto School of Medicine, University of Sao Paulo (FMRP-USP), Brazil.

Presented at the XII National Congress on Experimental Surgery of the Brazilian Society for the Development of Research in Surgery-SOBRADPEC, 2011, October 26-29 Ribeirao Preto-SP, Brazil. 